\title{
Investigation on Behavior of Unburnt Pulverized Coal in Blast Furnace
}

\section{Yuji IWANAGA}

Iron \& Steel Research Laboratories, Sumitomo Metal Industries, Ltd., Hasaki-machi, Kashima-gun, Ibaraki-ken, 314-02 Japan.

(Received on September 25, 1990; accepted in the final form on December 14, 1990)

In order to clarify the combustion reaction when PC (Pulverized Coal) is blown into the tuyeres of a blast furnace and the effects of resultant unburnt PC on reactions, in the furnace, some fundamental experiments were carried out. The main results obtained are as follows:

(1) Most of PC blown through the tuyeres rapidly burns in the raceway.

(2) Unburnt PC tends to adhere to the softened and fused ore bed.

(3) Unburnt PC adhering to the ore bed is consumed by the direct reduction of $\mathrm{FeO}$ and improves the softening and melting-down properties of ores effectively.

In this way, PC entering inside the blast furnace without burning was found to be consumed effectively.

KEY WORDS: ironmaking; blast furnace process; pulverized coal injection; coke; unburnt pulverized coal; gasification.

\section{Introduction}

Pulverized coal (hereinafter referred to as $\mathrm{PC}$ ) has been used more widely to have a stable operation of blast furnaces and to decrease the coke consumption. ${ }^{1,2)}$ Recent blast furnace operation has a problem on how to burn PG completely but this seems to have restriction on equipment and blowing conditions.

On the other hand, it has been empirically known that the injection of $\mathrm{PC}$ not only replaces coke partly with coal but also stabilizes the furnace performance. $\mathrm{PG}$ injection into the furnace has been recognized to have a greater effect than blast humidity but the reason has not been clear yet.

Unburnt PC was observed inside an operating blast furnace $^{3)}$ and it was reported ${ }^{4)}$ that most of unburnt $\mathrm{PC}$ was preferentially gasified by $\mathrm{CO}_{2}$ gas and thereby gave little effects on the pressure drop in the furnace. However, the behavior of unburnt PC in the blast furnace, namely the effects on gas flow and on various reactions in the furnace are not known. If unburnt $\mathrm{PG}$ generating in the furnace could be effectively consumed, a fairly large amount of PC injection into the furnace, use of various kinds of coal and mitigation of combustion and equipment conditions could be expected.

This paper describes the behavior of $P C$ in the blast furnace through the investigation of the effects of unburnt $\mathrm{PC}$ injection into packed beds on the change in its residual amount and on the high-temperature properties of sinter.

\section{Experimental Apparatus and Experimental Procedure}

\subsection{Combustion of Pulverized Coal}

A single coal particle (weighed 3 to $7 \mathrm{mg}$ and not a single particle in a strict sense) was burnt by spon- taneous ignition, and its combustion was observed.

Fig. 1 shows the schematic experimental apparatus. The combustion air was made to flow at a given rate (20 NL/min) through the packed bed of small alumina balls and was heated up to a given temperature (800 $1200^{\circ} \mathrm{C}$ ). A certain amount of PC was fixed to the end of the thermocouple and was put into a given position of the combustion chamber to burn. Temperature changes and combustion time were measured by the thermocouple. Further, the changes in the flames were detected through the condenser lens, amplified and connected to the electromagnetic oscillograph to measure ignition delay and combustion time. Australian coal crushed under 200 mesh having the properties given in Table I was used as a test PC.

\subsection{Behavior of Sinter in High Temperature Gases with Unburnt Pulverized Coal}

Fig. 2 shows the schematic experimental apparatus.

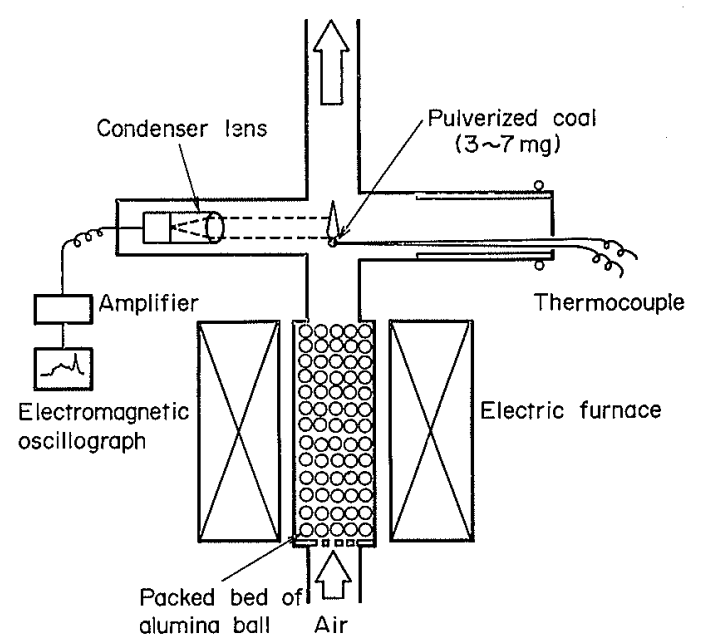

Fig. 1. Experimental apparatus for combustion of pulverized coal. 
Table 1. Properties of pulverized coal.

\begin{tabular}{|c|c|c|c|c|c|c|}
\hline \multirow{2}{*}{$\begin{array}{l}\text { FC } \\
(\%)\end{array}$} & \multirow{2}{*}{$\begin{array}{l}\text { VM } \\
(\%)\end{array}$} & \multirow{2}{*}{$\begin{array}{l}\text { Ash } \\
(\%)\end{array}$} & \multirow{2}{*}{$\begin{array}{l}\text { Density } \\
\left(\mathrm{g} / \mathrm{cm}^{3}\right)\end{array}$} & \multicolumn{3}{|c|}{ Ultimate analysis (\%) } \\
\hline & & & & G & $\mathrm{H}$ & $N$ \\
\hline 58.8 & 38.3 & 9.1 & 0.86 & 83.5 & 4.5 & 2.1 \\
\hline
\end{tabular}

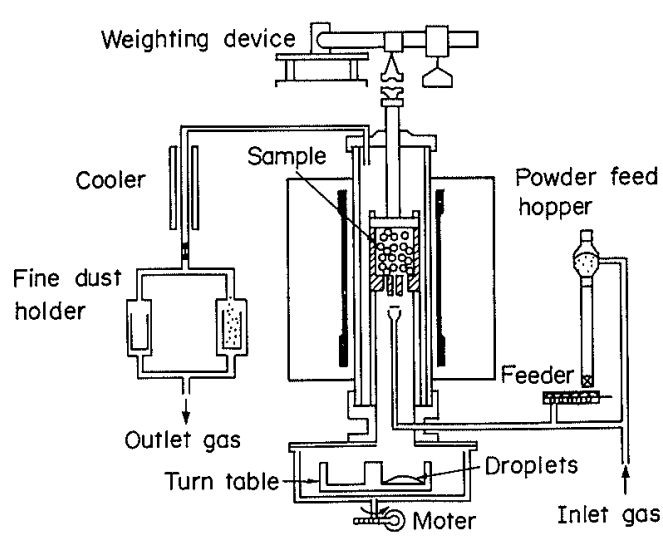

Fig. 2. Experimental apparatus.

Sinter or coke was packed in the reaction tube. The particle size of samples was restricted to $20 \pm 1 \mathrm{~mm}$ because of the tube diameter $(70 \mathrm{~mm})$. The bed was set to be $100 \mathrm{~mm}$ in height. Commercial sinter, the characteristics of which are shown in Table 2, was used as a sample. PC was prepared from the coal whose properties are shown in Table 1 and heated at $1500^{\circ} \mathrm{C}$ for $8 \mathrm{~h}$ to devolatilize. Table 2 shows the properties of the resultant PC. A given amount of the PG was fed by the screw feeder, transferred by $\mathrm{N}_{2}$ and blown into the furnace with the reducing gas.

The experiments were carried out changing the temperature, the gas composition and the load. ${ }^{5)}$ The pressure drop in the sample layer and its shrinkage were measured and the waste gas was analysed. Most of the unburnt PC blown into the furnace remained in the sample layer, whereas the rest was discharged out of the system by the gas and was collected by two cyclones alternately at a given interval. The weight of materials captured in the sample layer was measured after the experiment.

Sintered ores, began to fuse over $1000^{\circ} \mathrm{C}$, and this makes it difficult to measure the powder amount in the packed bed. In this case, the amount was calculated from the powder balance, because it was confirmed that the amount of the powder remaining in the sample in the low-temperature region was equal to the difference between the supply and the recovery.

\section{Experimental Results and Discussion}

\subsection{Unburnt Pulverized Coal Caused by Imperfect Com- bustion}

Fig. 3 shows the typical temperature changes and the results of measurement by the electromagnetic oscillograph. Pulverized coal at the point (a) in the furnace was heated and ignited at the point (b). The amount of volatile components and flame brightness decrease during the gaseous combustion and it finishes
Table 2. Properties of samples.

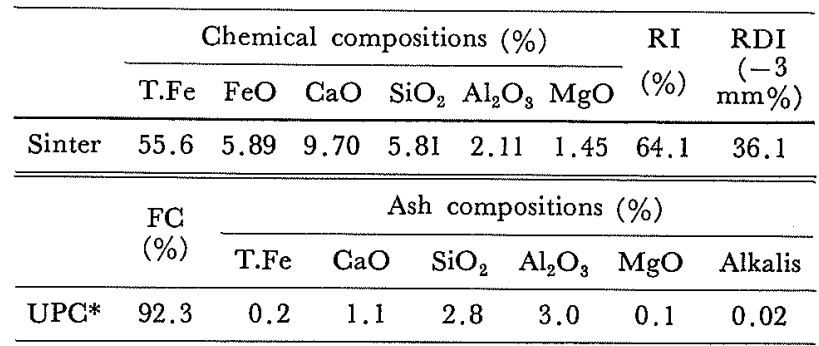

* Unburnt Pulver Coal

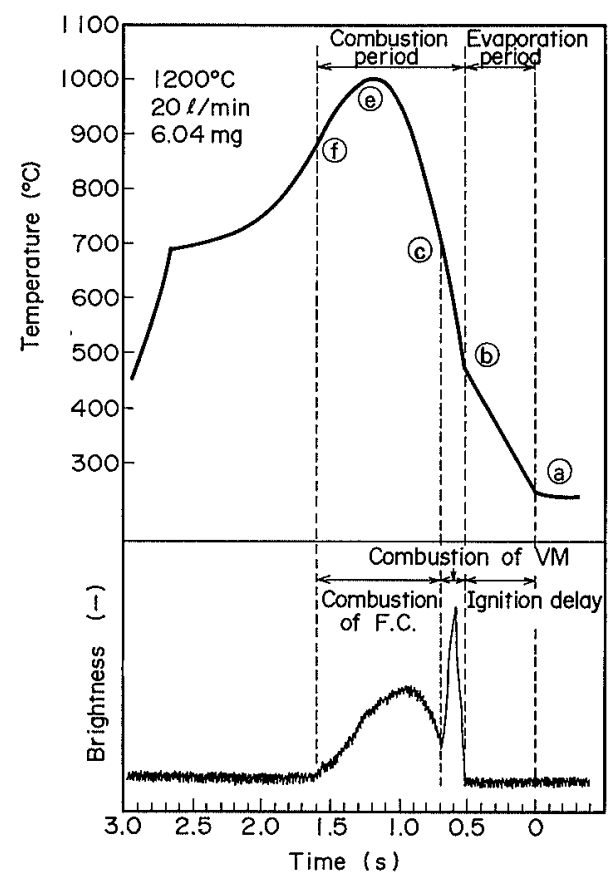

Fig. 3. Burning history of pulverized coal.

at the point (c). Subsequently, a part of residual carbon particles ignites and initiates solid combustion, reaching the maximum temperature at the point (e). Solid combustion finishes at the point (f), leaving ashes.

Fig. 3 shows that the ignition delay, the gaseous combustion time and the solid combustion time are about 500, 200 and $900 \mathrm{~ms}$, respectively, and that the solid combustion time is about 4 to 5 times as long as that of gaseous combustion. Application of the square $\left.{ } \mathrm{aw}^{6}\right)$ to the combustion temperature and the particle size enables to calculate the gaseous combustion and the solid combustion time in this experimental condition as follows:

$$
\begin{aligned}
& D_{0}^{2}=k_{g} t_{g} \ldots \ldots \ldots \ldots \ldots \\
& D_{0}^{2}=k_{s} t_{s} \ldots \ldots \ldots \ldots \ldots \\
& D_{0}=2\left(\frac{3}{4 \pi \rho} M\right)^{1 / 3} \\
& k_{g}=0.0536\left(\mathrm{~cm}^{2} / \mathrm{s}\right) \\
& k_{s}=0.0119\left(\mathrm{~cm}^{2} / \mathrm{s}\right)
\end{aligned}
$$

where, $D_{0}:$ initial particle size of PC $(\mathrm{cm})$

$k_{g}$ : gaseous combustion rate $\left(\mathrm{cm}^{2} / \mathrm{s}\right)$

$k_{s}:$ solid combustion rate $\left(\mathrm{cm}^{2} / \mathrm{s}\right)$

$M:$ weight of $\mathrm{PC}(\mathrm{g})$ 
$t_{g}:$ gaseous combustion time (s)

$t_{s}:$ solid combustion time (s)

$\rho$ : density of PG $\left(\mathrm{g} / \mathrm{cm}^{3}\right)$.

On the other hand, D. A. Frank Kamenetskii ${ }^{7}$ have confirmed that ignition delay time is dependent only on temperature and derived the following equation from the unsteady heat balance regarding heat generation, radiation and heat accumulation:

$$
t_{l l}=\frac{C_{p} \cdot \rho_{q}}{Q} \cdot \frac{R \cdot \mathcal{T}_{e}^{2}}{E} \cdot \frac{1}{Z} e^{E / R T_{a}}
$$

where, $C_{p}: \quad$ specific heat $\left(\mathrm{kcal} / \mathrm{kg} \cdot{ }^{\circ} \mathrm{C}\right)$

$E$ : activation energy (kcal $/ \mathrm{mol})$

$Q:$ heat of reaction $(\mathrm{kcal} / \mathrm{kg})$

$R:$ gas constant $\left(\mathrm{kcal} / \mathrm{mol} \cdot{ }^{\circ} \mathrm{C}\right)$

$t_{d}:$ ignition delay time $(\mathrm{s})$

$T_{a}$ : temperature $\left({ }^{\circ} \mathrm{C}\right)$

$Z:$ constant $(-)$

$\rho_{q}:$ gas density $\left(\mathrm{kg} / \mathrm{m}^{3}\right)$.

Substitution of physical-property into Eq. (6) and calculation by using the experimental results led to the $Z$ value to be of 5.05 .

When Eqs. (4) and (5) are applied, the resultant combustion time of -200 mesh $\left(74 \times 10^{-3} \mathrm{~mm}\right) \mathrm{PC}$ is,

$$
\begin{aligned}
& t_{g}=\left(74 \times 10^{-4}\right)^{2} / 0.0536=1.02 \times 10^{-3} \\
& t_{s}=\left(74 \times 10^{-4}\right)^{2} / 0.0119=4.60 \times 10^{-3}
\end{aligned}
$$

This shows that the combustion is completed in the order of $10^{-3} \mathrm{~s}$.

Fig. 4 suggests that PC injected through the tuyeres is first heated up by the blast, followed by combustion. The residence time of $\mathrm{PC}$ in the raceway, on the other hand, is only from 10 to $30 \mathrm{~ms}$. This means combustion seems to be completed in the raceway from the viewpoint of velocity. Taking the ignition delay before gaseous combustion into account, however, the probability for $\mathrm{PC}$ to go out of the raceway before solid combustion may be possibly high.

Takeda et $a l .{ }^{3)}$ investigated the combustion of $\mathrm{PC}$ in a blast furnace by using a tuyere probe inserted from the sidewall and reported that the char was sampled out of the raceway as an unburnt material. Deguchi et al. ${ }^{4}$, moreover, performed a series of experiments in which $\mathrm{PC}$ was injected into a combustion test furnace and found out that a part of $P C$ remained unburnt in the raceway accumulating in the furnace. As the studies of coke-filled furnaces ${ }^{8}$ the combustion rate of $\mathrm{PG}$ becomes higher with the enrichment of

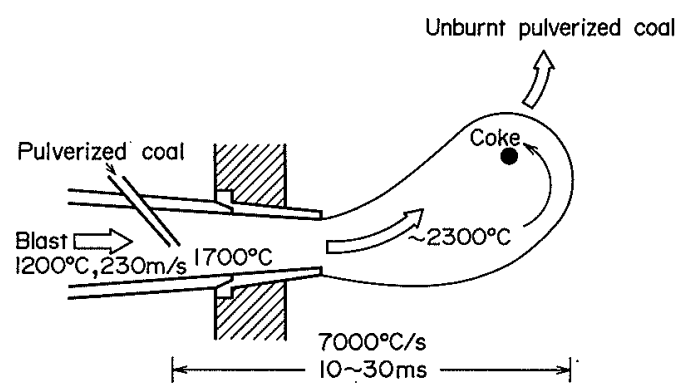

Fig. 4. Conditions of coal injection at tuyere and that of unburnt pulverized coal during ascent. oxygen. However, even if $\mathrm{PC}$ is injected into an actual blast furnace, combustion efficiency of $\mathrm{PC}$ will be at most $90 \%$ in despite of the oxygen enrichment and $10 \%$ of unburnt PC will inevitably flow out from the raceway and move upward in the furnace.

\subsection{Remaining Position and Amount of Unburnt Pulver- ized Coal}

Fig. 5 shows the change of the amount of residual fines in the coke-packed bed as a function of the time when the devolatilised PG is blown into the packed bed at room temperature and suggests that the amount of residual fines in the packed bed increases nearly in proportion to the time. Therefore, the slope of the line means residing rate of fines. Its relation with blowing conditions was examined and the results are shown in Fig. 6. When the experimental conditions

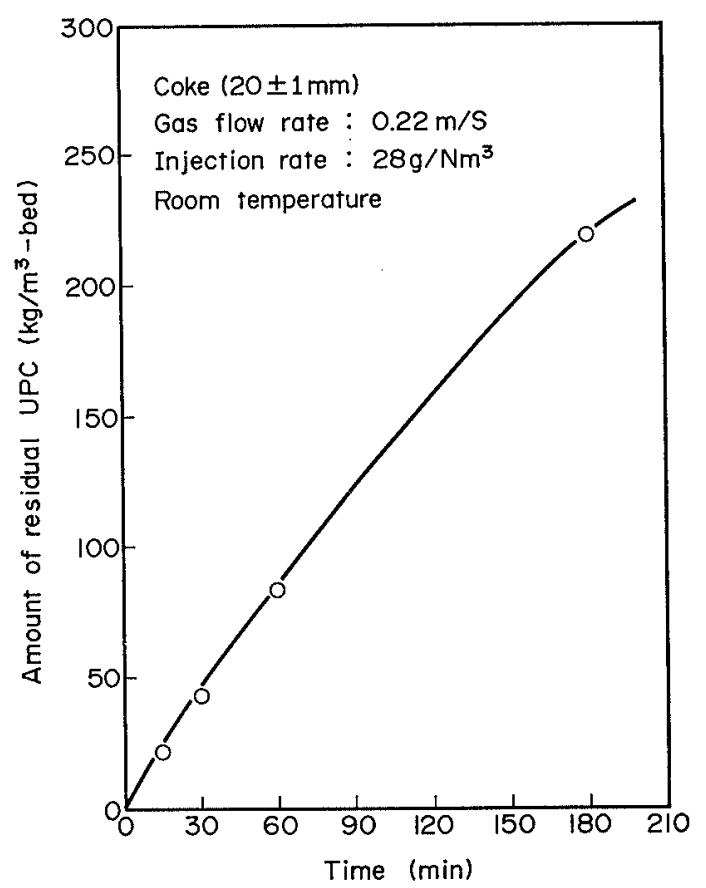

Fig. 5. Change of residual unburnt pulverized coal with time.

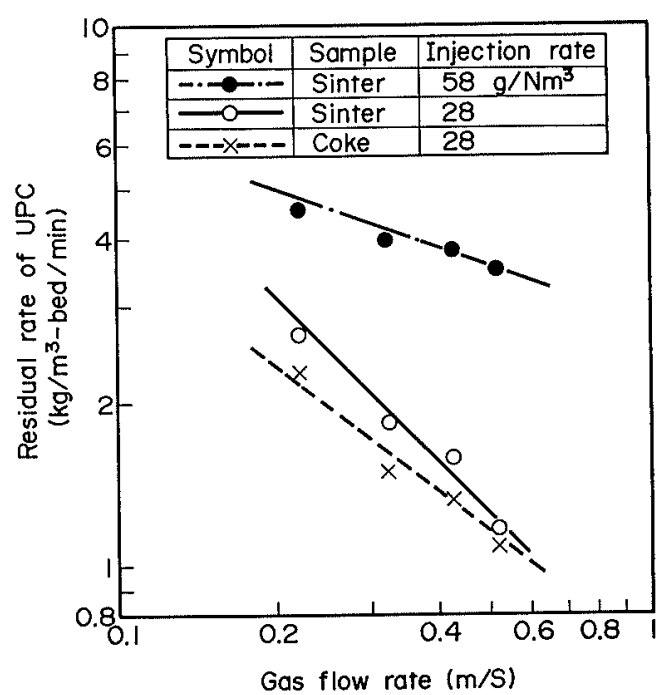

Fig. 6. Effects of gas flow rate, injection rate and sample kind on residual rate of unburnt pulverized coal. 

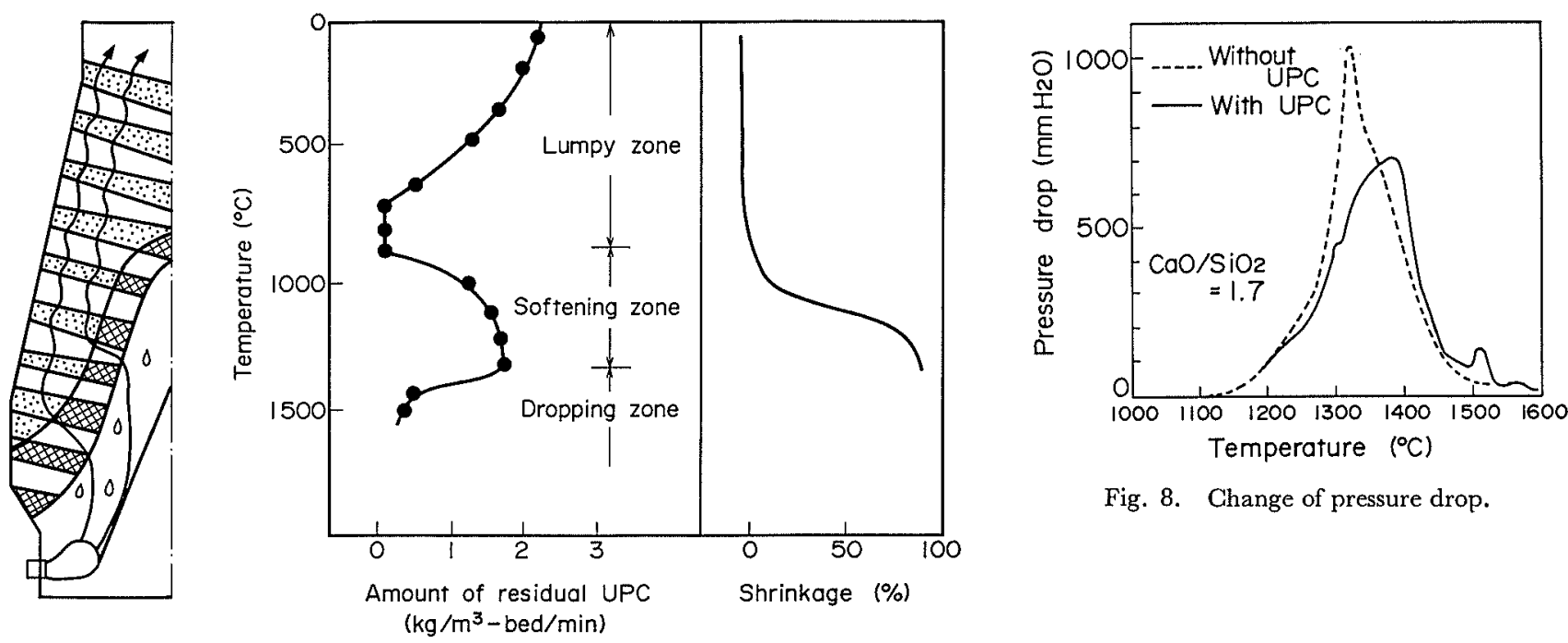

Fig. 8. Change of pressure drop.

Fig. 7. Change of amount of residual unburnt pulverized coal in a hypothetical blast furnace.

are fixed, there exists little difference between the amounts of residual fines in the sinter bed and the coke bed. Low gas velocities increase the amount of residual fines and this is remarkable in the lower gas velocity range. It is natural, of course, that the increased blowing amount should make the residual fines greater.

In the case of the coke packed bed, little difference was observed in the amount of residual fines between in the hot and cold states. In the case of sinter packed bed, on the other hand, high temperatures give rise to its softening, contraction and dripping to change the amount of residual fines remarkably more. Fig. 7 shows the longitudinal distribution of amount of residual fines to the height of a hypothetical blast furnace. The unburnt $\mathrm{PC}$ generated in the raceway goes up with the gas flow and its amount in the fused zone increases rapidly. The amount of unburnt $\mathrm{PG}$ collected at about $1400^{\circ} \mathrm{G}$ zone is maximum, decreasing gradually as the temperature decreases further. This may be because of the decreased contraction ratio and the increased void ratio. Although the retention of unburnt $\mathrm{PC}$ is not observed in the lumpy zone corresponding to $600-800^{\circ} \mathrm{G}$ zone, the fines of unburnt $\mathrm{PG}$ begin to reside again due to the decrease in gas flow rate.

\subsection{Effect of Unburnt Pulverized Coal on High-tempera- ture Properties of Sinter}

Fig. 8 shows the temperature dependence of the pressure drop. There are several obvious steps in the softening and fusion process. The first step relates to initial fusion occurring at about $1100^{\circ} \mathrm{C}$, where indirect reduction proceeds. The amount of the molten slag increases as the temperature rises and it tends to fill the voids, resulting in a rapid increase in the pressure drop. The subsequent step concerns direct reduction which changes $\mathrm{FeO}$-rich slag to little or no $\mathrm{FeO}$ slag or to a metal. As the direct reduction proceeds, the amount of molten slag decreases and the permeability gradually increases. In this step, high-

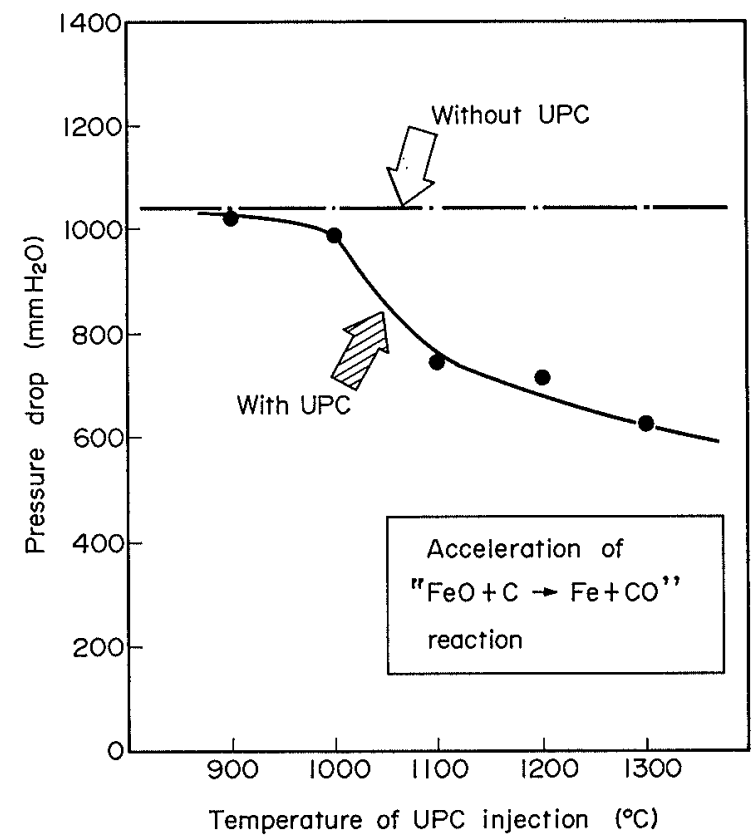

Fig. 9. Effect of temperature of unburnt pulverized coal injection on pressure drop.

fluidity slag containing $\mathrm{FeO}$ begings to drip.

Fig. 8 indicates that pressure drop in the softening and fusion zone corresponding to $1200-1400^{\circ} \mathrm{C}$ becomes small when the unburnt $\mathrm{PG}$ is injected into the furnace. This suggests that the unburnt $\mathrm{PG}$ is consumed by the direct reduction of $\mathrm{FeO}$ to make the amount of molten slag less and softening resistance more since the difference of pressure drop becomes greater with the increasing injection temperature as shown in Fig. 9.

During the softening and melting processes, two kinds of slag, high-FeO and low-FeO slag, are produced. The former has sufficient fluidity, while the latter becomes a residual slag which makes the metal dripping. Fig. 10 shows the effects of the injected unburnt $\mathrm{PG}$ on the relations between the melting down temperatures and the basicity. In both cases, the 


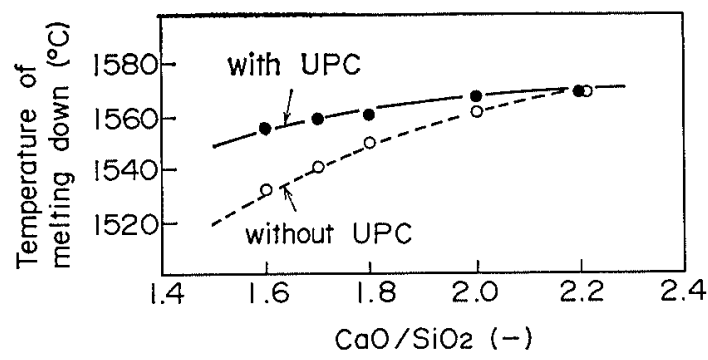

Fig. 10. Change of melting down properties.

melting down temperature rises with the increasing basicity and the curve shifts upward when the unburnt PC is injected. In addition, the effect of the injected unburnt PC tends to be smaller with the increasing basicity. Thus, the presence of the unburnt PG has a strong affects on the melting down properties.

The change in the relative proportions of the dripped solid and the residual slag with temperature was calculated on the basis of the phase diagram of the multicomponent slags. ${ }^{9}$ ) It is evident that the proportion of the solid in the residual slag is generally higher than that in the dripped slag.

The presence of the unburnt PG strongly affects the dripping properties of the metal. The unburnt $\mathrm{PC}$ reacts with the $\mathrm{FeO}$-rich slag and decrease the amount of $\mathrm{FeO}$ changing the proportions of solid and liquid and then its fluidity. The reaction makes the high-viscosity slag and it shields the metal from coke effectively preventing the metal from carburization and melting down.

The unburnt PG may change the carbon concentration in the metal and the slag composition. Fig. 11 shows the carbon concentration in the dripped metal plotted in the $\mathrm{Fe}-\mathrm{C}$ equilibrium diagram. The carbon in the metal increases as the temperature rises and helps the reduction. When the carbon concentration of the metal reaches that of the solidus of austenite, the metal begins to melt. In this experiment, it begins to drop at $100-150^{\circ} \mathrm{C}$ higher temperatures than the solidus of austenite. In the presence of unburnt PC the same behavior is seen as that without unburnt $\mathrm{PC}$ in the phase diagram. If the beginning temperatures of melting down are equal, the carbon concentration in the presence of unburnt $\mathrm{PC}$ coincides with that without unburnt PC.

Fig. 12 shows the slag compositions before the experiments and that in the sample layer after the experiments with or without the unburnt PC. When the unburnt $\mathrm{PC}$ is injected, the concentrations of $\mathrm{CaO}, \mathrm{SiO}_{2}$ and $\mathrm{Al}_{2} \mathrm{O}_{3}$ increase slightly, resulting possibly from the ashes. On the other hand, the concentration of $\mathrm{FeO}$ decreases remarkably. Since no change in the carbon concentration in the metal is observed, these facts prove that the unburnt $P C$ is consumed selectively by the direct reduction of $\mathrm{FeO}$.

\section{Conclusion}

In order to clarify the combustion reaction when $P G$ is injected into the tuyeres of a blast furnace and

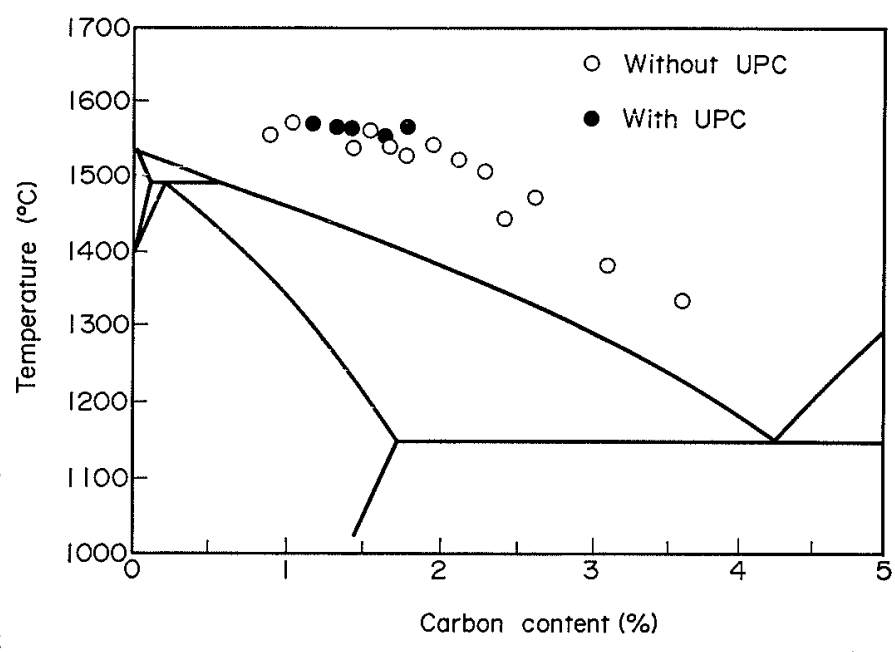

Fig. 11. Relation between melting down temperature and carbon content.
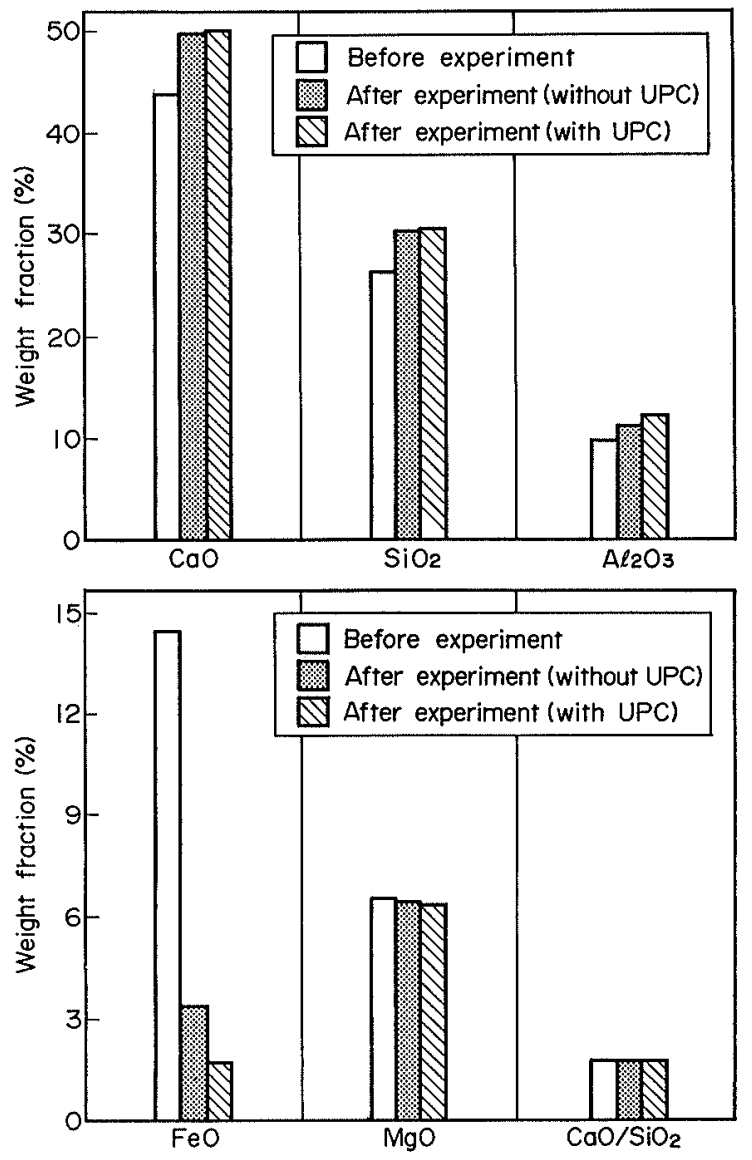

Fig. 12. Change of slag components.

the effects of the resultant unburnt PC on in-furnace reactions, some basic experiments were carried out and the following have been found.

(1) Most of PC injected through the tuyeres burns rapidly in the raceway but a part of $P C$ is carried away out of the raceway without burning.

(2) The unburnt PC tends to stay in the softened and fused ore bed. The unburnt PG adhering to the ore bed is consumed by the direct reduction of $\mathrm{FeO}$ and improves effectively the high-temperature properties of the ore.

In this way, even when $\mathrm{PC}$ injected into the blast 
furnace does not burn completely, it was found that is consumed effectively.

\section{REFERENCES}

1) M. Guili, G. Hanniker, J. Koster, K. Kreibich, J. M. van Langen, Y. de Lassat de Pressigny and A. Poos: Proc. of European Ironmaking Congress, VDEh, Düsseldorf, (1986), IV $/ 2$.

2) K. Takeda, S. Miyagawa and S. Taguchi: Tronmaking Conf. Proc., Vol, 49, ISS-AIME, Warrendale, PA, (1990), 455.

3) K. Takeda, S. Taguchi, T. Fukutake, H. Kato, N. Taka- shima and T. Nakai: Tetsu-to-Hagané, 72 (1986), S871.

4) M. Deguchi, K. Shibata and J. Fukuoka: CAMP-ISIJ, 1 (1988), 70.

5) Y. Iwanaga: Tetsu-to-Hagané, 68 (1982), 2223.

6) T. Sagai and M. Saito: J. Fuel Soc. Jpn., 60 (1981), 183.

7) D. A. Frank Kamenetskii: Diffusion and Heat Exchange in Chemical Kinetics, Princeton Univ. Press, Princeton, NJ, (1969).

8) S. Yabe, I. Kurashige, T. Miyazaki, T. Iba, M. Kojima, Y. Shoji and Y. Kamei: Ironmaking Proc., Vol. 40, AIME, Warrendale, PA, (1981), 468.

9) G. Clixby: Ironmaking Steelmaking, 13 (1986), 169. 